\title{
Pengaruh Penataan Bangunan dan Lingkungan Terhadap Resiko Bencana Kebakaran Di Kelurahan Nyamplungan Kota Surabaya
}

\author{
Arimudin Nurtata dan Adjie Pamungkas \\ Jurusan Perencanaan Wilayah dan Kota, Fakultas Teknik Sipil dan Perencanaan, Institut Teknologi \\ Sepuluh Nopember (ITS) \\ Jl. Arief Rahman Hakim, Surabaya 60111 Indonesia \\ e-mail: adjie.difi@gmail.com
}

\begin{abstract}
Abstrak-Kota Surabaya menjadi salah satu kawasan rawan kebakaran di Indonesia. Pada tahun 2014 kejadian kebakaran di kota Surabaya sebanyak 596 kejadian. Salah satu kawasan yang mengalami kebakaran tiap tahunnya berada di kelurahan Nyamplungan. Dalam menghadapi kebakaran dibutuhkan suatu alat yang efektif dan efisien yang sesuai dengan karakteristik bangunan dan lingkungannya. Oleh karena itu, penelitian ini berusaha mengidentifikasi karakteristik penataan bangunan dan lingkungan di kelurahan Nyamplungan dalam mengurangi resiko kebakaran. identifikasi karakteristik penataan bangunan dan lingkungan pada kelurahan Nyamplungan menggunakan teknik Walkthrough Analysis. Hasil penelitian menunjukkan bahwa karakteristik bangunan, lingkungan, dan sarana kebakaran pada kelurahan Nyamplungan meningkatkan resiko bencana kebakaran. Pada karakteristik pembentuk solid, void dan linkage pada kelurahan Nyamplungan dapat mengurangi resiko bencana kebakaran sehingga karakteristik tersebut bisa dioptimalkan dalam usaha - usaha mengurangi resiko kebakaran.
\end{abstract}

Kata Kunci-Kebakaran, Penataan Bangunan dan Lingkungan,

Pengurangan Resiko .

\section{V.PENDAHULUAN}

$\mathrm{K}_{\mathrm{b}}^{\mathrm{A}}$ AWASAN perkotaan dengan lahan terbangun yang cukup besar menjadi salah satu penyebab rawan terjadi kebakaran. Kebakaran menyumbang 15 persen dari total bencana yang terjadi di Indonesia, khusunya di perkotaan dengan kepadatan hunian tinggi. Kota Surabaya merupakan salah satu kota yang memiliki kepadatan bangunan yang tingi sering mengalami kebkaran tiap tahunnya. Tercatat pada pada tahun 2012 terjadi sebanyak 573 kejadian, sedangkan tahun 2013 menurun menjadi 397 kejadian. Tahun 2014 kejadian kebakaran kembali meningkat yaitu sebanyak 596 kejadian. [1]

Salah satu kawasan yang mengalami kebakaran tiap tahunnya adalah kelurahan Nyamplungan. Kebakaran di kelurahan Nyamplungan pada tahun 2013 melibatkan 4 unit. Kebakaran terjadi lagi di kelurahan Nyamplungan melibatkan 1 unit PMK yang mengakibatkan 3 rumah rusak pada bulan Maret tahun. Kebakaran juga mengakibatkan 6 rumah rusak di kelurahan Nyamplungan yang melibatkan 12 unit PMK pada Bulan September 2014. Hal mendasar yang menjadi faktor risiko kejadian kebakaran diperkirakan akibat pola perilaku masyarakat, baik kasus hubungan arus pendek maupun ledakan tabung LPG

Dalam menghadapi bencana kebakaran di perkotaan sudah terdapat perundang - undangan yang telah mengatur penanggulangan bencana kebakaran perkotaan yaitu Kepmen PU No. 10/KPTS/2000dan Kepmen PU No. 11/KPTS/2000. Namun, dalam praktek penanggulangan bencana kebakaran perkotaan masih belum optimal akibatnya jumlah kejadian kebakaran masih sering terjadi.

Permasalahan tersebut mengindikasikan bahwa usaha usaha penanggulangan bencana kebakaran di perkotaan belum sesuai dengan karakteristik kawasan baik bangunan maupun lingkungannya yang rawan terjadi bencana kebakaran. oleh karena itu perlu identifikasi kawasan baik bangunan dan lingkungan dalam mengurangi resiko bencana kebakaran.

\section{METODE PENELITIAN}

\section{A. Metode Pengumpulan Data}

Metode pengumpulan data yang digunakan dalam penelitian ini adalah teknik survei primer dan sekunder. Survei primer melalui observasi pada kawasan penelitian yang telah dibagi menjadi 6 blok sesuai dengan karakteristik yang sama dengan alat rekam berupa kamera. Survei sekunder dilakukan dengan survei literatur berupa buku yang membahas tentang bahaya kebakaran, pedoman maupun perundang - undangan yang berhubungan dengan kebakaran perkotaan dan Laporan penelitian maupun jurnal yang membahas bahaya kebakaran perkotaan.

\section{B. Metode Analisis}

Metode Analisis yang digunakan adalah analisis Walkthrough. Analisis tersebut merupakan analisis deskriptif mengenai penggambaran lokasi. Analisis ini mengkaji kualitas perkotaan yang dilakukan dengan cara berjalan melalui daerah dengan mengamati dan melihat kesan yang dirasakan di sepanjang jalan melalui rekaman gambar eksisting dari lokasi studi. Teknik ini menggunakan metode grafis dalam melakukan pengamatan pada saat merekam objek. Sehingga dalam pembahasannya, analisis ini menggunakan sistem informasi 
gambar yang tersusun berdasarkan lokasi-lokasi perjalanan survey. Teknik ini memiliki 3 tipe pengamatan, diantaranya:

1) Single Directional View

Merupakan teknik yang menggunakan perangkat atau alat sederhana untuk peta interaktif. Alat tersebut berupa panah dalam peta di suatu titik untuk melihat foto tertentu. Panah tersebut menunjukkan pandangan streetscape dalam foto.

\section{2) Linier Side View}

Merupakan teknik yang digunakan untuk menggambarkan suasana sebuah area melalui jalur terkait. Pandangan yang ditampilkan ialah pandangan berurutan (serial view). Pandangan tersebut memperlihatkan simulasi mengenai bagaimana para pejalan kaki bergerak dan melangkah ke depan; serta memandang ke samping untuk menikmati dan melihat bangunan dari depan (tampak depan)

3) Four Directional View

Merupakan teknik yang digunakan untuk pencitraan nodes. Aplikasi teknik ini menggunakan tampilan foto nodes yang diambil dari arah menyilang dari setiap sudutnya. Teknik ini lebih berfokus pada sudut jalan yang merupakan area kritis dari bentuk kota. Sudut merupakan posisi yang sangat berarti dari sebuah path. Sudut juga merupakan posisi yang berarti sebagai titik penting nodes.

Berdasarkan penjelasan tersebut maka dalam panelitian akan menggunakan analisis Walkthrough berupa Single Directional View dan Linier Side View. Hal ini dikarenakan kebutuhan penelitian ini adlaah kesan yang ditentukan dari beberapa kriteria baik secara tampak depan bangunan maupun secara blok.

\section{HASIL DAN PEMBAHASAN}

Dalam mengidentifikasi karaktersitik penataan bangunan dan lingkungan pada kawasan penelitian menggunakan teknik Walkthrough Analysis. Teknik analisis tersebut dilakukan dengan mengambil gambar bentuk bangunan dan lingkungan pada tiap blok kemudian diintepretasikan sesuai gambar tersebut. Berikut tabel hasil pengamataan karakteristik penataan bangunan dan lingkungan pada tiap blok.

\section{A. Indikator fisik bangunan}

Karakteristik pada indikator fisik bangunan antara lain karakteristik jarak antar bangunan, ketinggian bangunan, fungsi bangunan, jenis material bangunan dan ketersediaan ruang terbuka. Hampir seluruh karakteristik pada indikator fisik bangunan pada tiap blok sama seperti jarak antar bangunan kurang dari 1 meter. Jarak aman bangunan untuk tinggi bangunan sampai 8 meter sebesar 3 meter[2]. ketinggian bangunan sekitar 2-3 lantai dimana sama dengan 8-12 meter membuat karakteristik ini meningkatkan resiko kebakaran.

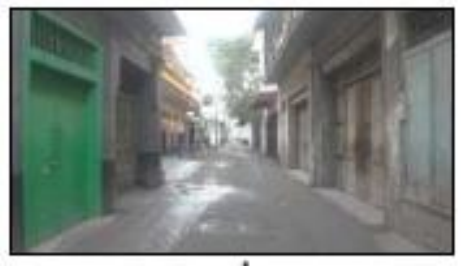

Gambar 1 Kondisi jarak antar bangunan dan tinggi bangunan Kelurahan Nyamplungan
Jenis material bangunan yang digunakan untuk dinding luar berupa batu bata. Bangunan dengan jenis material batu bata tergolong kontruksi mudah terbakar[3]. Hal tersebut juga membuat karakteristik jenis material bangunan meningkatkan resiko kebakaran. Ketersediaan ruang terbuka yang kurang untuk mnjadi titik evakuasi meningkatkan resiko kebakaran di kelurahan Nyamplungan. Fungsi bangunan yang mendominasi pada tiap blok antara lain hunian dan perdagangan dan jasa. fungsi bangunan perumahan tergolong angka resiko kebakaran 7 dengan resiko kebakaran rendah sedangkan fungsi bangunan perdagangan dan jasa tergolong angka resiko kebakaran [4]. Namun akibat bangunan yang sangat berdekatan maka fungsi hunian maupun fungsi perdagangan dan jasa memiliki resiko kebakaran tinggi.

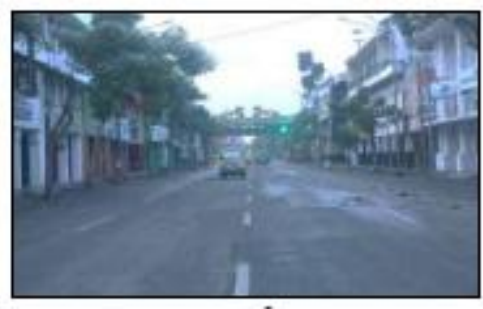

Gambar 2 Fungsi Bangunan Perdagangan dan Jasa

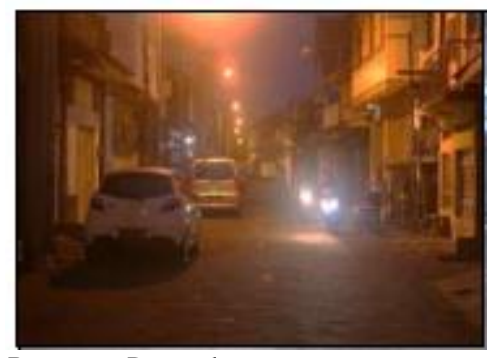

Gambar 3 Fungsi Bangunan Perumahan

\section{B. Indikkator lingkungan}

Karakteristik pada indikator lingkungan antara lain karakteristik hirarki jalan, sumber air dan jaringan listrik. Karakteristik hirarki jalan pada tiap blok berbeda-beda. Lebar jalan sebesar 6 meter berada di blok 1. Lebar jalan sebesar 8 meter berada di blok 3 . Lebar jalan sebesar 12 meter berada di blok 2, blok 4 dan blok 6. Lebar jalan sebesar 8 meter dan 12 meter berada di blok 5 . Hampir jalan semua blok digunakan untuk arus kendaraan dua arah kecuali jalan yang berada di blok 3 dan blok 5 digunakan hanya untuk arus kendaraan satu arah. Jalan yang bisa dilewati mobil pemadam kebakaran memiliki lebar 6 meter[5]. Hal tersebut membuat seluruh jalan dapat digunakan sebagai jalur mobil pemadam kebakaran. Namun, beberapa jalan terdapat parkir on the street sehingga mengganggu arus kendaraan. Oleh karena itu, pada beberapa jalan tidak dapat dilewati oleh mobil kebakaran sehingga meningkatkan resiko kebakaran. 


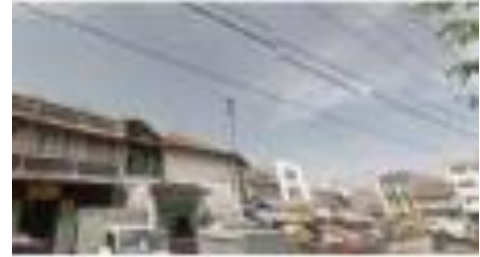

Gambar 4 Jalan Yang Terdapat Parkir On The street

Karakteristik sumber air yang dapat digunakan dalam usaha pemadaman api hampir tiap blok sama yaitu berupa air PAM. Blok 5 dan 6 selain berupa air PAM terdapat aliran sungai yang dapat digunakan dalam usaha pemadaman api. Sumber air minimal memiliki debit 38 liter/detik[6]. Hal tersebut membuat hampir sebagaian kawasan memiliki karakteristik sumber air yang dapat meningkatkan resiko kebakaran.

Karakteristik jaringan listrik berupa tiang listrik dan kabel listrik hampir pada tiap blok berdekatan dengan bangunan. Jarak aman tiang sebesar 1 meter dari atap rumah[7]. Hal tersebut membuat karakteristik jaringan listrik meningkatkan resiko kebakaran.

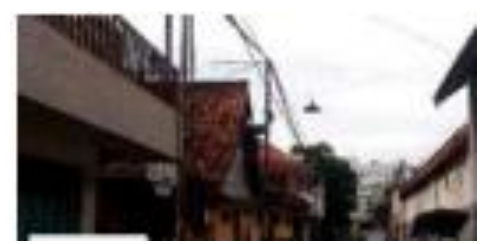

Gambar 5 Kondisi Tiang Listri Yang Berdekatan dengan Bangunan

\section{Indikator sarana kebakaran}

Karakteristik pada indikator sarana kebakaran antara lain karakteristik jalur keluar bangunan, APAR, dan jalur evakuasi. Seluruh blok belum memiliki sarana kebakaran padahal kejadian kebakaran pada kawasan sering terjadi. Hal tersebut membuat karakteristik pada indikator sarana kebakaran meningkatkan resiko kebakaran.

\section{Indikator kriteria penanggulangan kebakaran}

Karakteristik pada indikator kriteria penanggulangan kebakaran antara lain fungsi pengaturan pola, sistem pengaturan pola, elemen pembentuk solid, elemen pembentuk void, elemen pembentuk linkage secara visual, elemen pembentuk linkage secara struktural, dan elemen pembentuk linkage secara kolektif. Karakteristik fungsi pengaturan pola Tiap blok berbeda - beda antara lain fungsi permukiman berada di blok 1, fungsi perdagangan dan jasa serta permukiman berada di blok 2 dan blok 3, fungsi perdagangan dan jasa berada di blok 4 dan blok 5 , dan fungsi pergudangan berada di blok 6. fungsi bangunan perumahan tergolong angka resiko kebakaran 7 dengan resiko kebakaran rendah sedangkan fungsi bangunan perdagangan dan jasa tergolong angka resiko kebakaran [8]. Namun akibat bangunan yang sangat berdekatan maka fungsi hunian maupun fungsi perdagangan dan jasa memiliki resiko kebakaran tinggi. Kemudian karakteristik sistem pengaturan pola pada semua blok berupa sistem heterogen yaitu bentuk bangunan berbeda- beda. Hal tersebut membuat usaha dalam mengurangi resiko kebakaran sulit karena bentuk tiap bangunan berbeda-beda sehingga karakteristik ini meningkatkan resiko kebakaran.

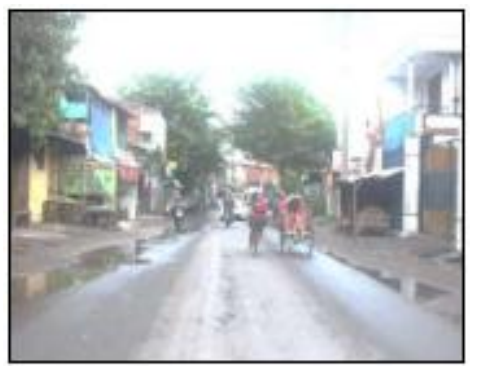

Gambar 6 Bentuk Bangunan yang Berbeda - Beda Pada Kelurahan Nyamplungan

Pada karakteristik elemen pembentuk solid pada semua blok berupa blok medan yaitu bentuk bangunan yang menjadi satu membentuk suatu blok. Hal tersebut membuat mengurangi resiko kebakaran karena mempermudah identifikasi karakteristik sebagai acuan dalam usaha mengurangi resiko kebakaran.

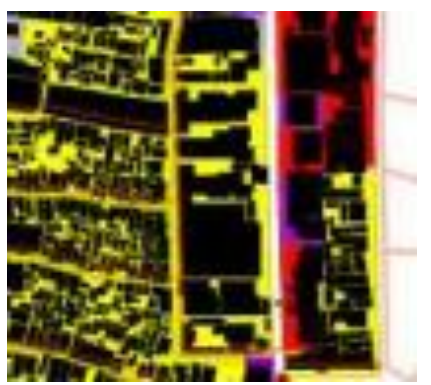

Gambar 7 Blok Perumahan yang berada di Kelurahan Nyamplungan

Hampir semua blok memiliki karakteristik elemen pembentuk void berupa sistem linier tertutup kecuali blok 6 berupa sistem linier terbuka. Elemen void sistem linier tertutup yang linier bersifat linier yang kesannya tertutup sedangkan sistem terbuka linier bersifat linier dan terbuka[9]. Keduanya dapat mengurangi resiko kebakaran sebagai titik evakuasi serta jalur evakuasi ketika terjadi kebakaran.
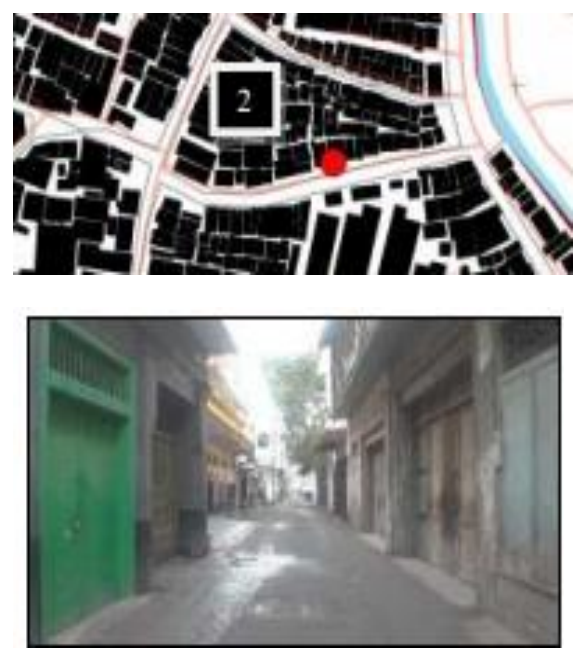

Gambar 8 Kondisi Elemen Pembentuk void Berupa Sistem Linier Tertutup 

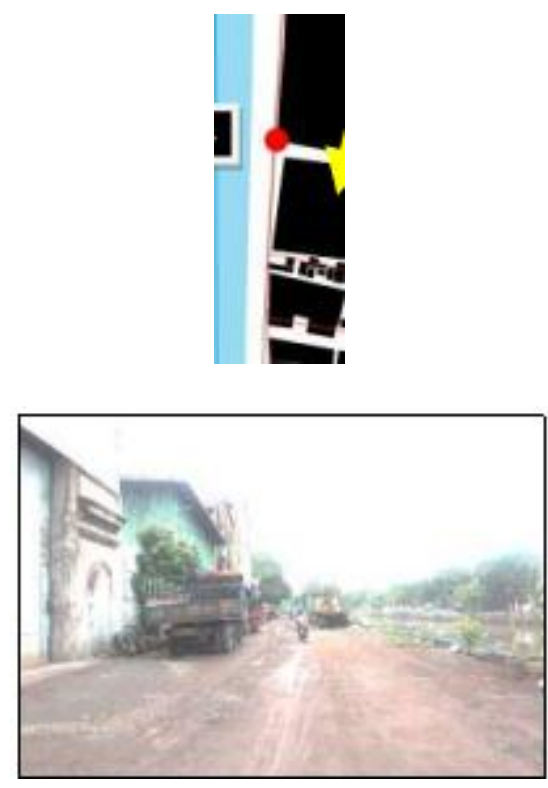

Karakteristik Indikator Lingkungan Fisk bangunan dan sarana kebakaran

\begin{tabular}{|c|c|c|c|c|c|c|c|c|c|c|c|}
\hline \multirow[b]{2}{*}{ Blok } & \multicolumn{3}{|c|}{ Indikator Lingkungan Bangunan } & \multicolumn{5}{|c|}{ Indikator Fisik Bangunan } & \multicolumn{3}{|c|}{ Indikator Sarana Kebakaran } \\
\hline & $\begin{array}{l}\text { Hirarki } \\
\text { Jalan }\end{array}$ & $\begin{array}{l}\text { Sumber } \\
\text { air }\end{array}$ & $\begin{array}{c}\text { Jaringan } \\
\text { listrik }\end{array}$ & $\begin{array}{c}\text { Jarak } \\
\text { antar } \\
\text { bangunan }\end{array}$ & $\begin{array}{c}\text { Ketinggian } \\
\text { bangunan }\end{array}$ & $\begin{array}{c}\text { Fungsi } \\
\text { bangunan }\end{array}$ & $\begin{array}{c}\text { Jenis } \\
\text { materia } \\
\text { bangunan }\end{array}$ & $\begin{array}{l}\text { Ruang } \\
\text { terbuka }\end{array}$ & $\begin{array}{c}\text { Jalur } \\
\text { darurat }\end{array}$ & APAR & $\begin{array}{c}\text { Jalur } \\
\text { evakuasi }\end{array}$ \\
\hline 1 & $\begin{array}{l}\text { lebar } \\
\text { jalan } 6 \\
\text { meter }\end{array}$ & $\begin{array}{l}\text { air } \\
\text { PAM }\end{array}$ & & & & Permukiman & & & & & \\
\hline 2 & $\begin{array}{l}\text { lebar } \\
\text { jalan } 12 \\
\text { meter }\end{array}$ & air PAM & $\Xi$ & & & $\begin{array}{c}\text { Permukiman } \\
\text { dan } \\
\text { perdagangan } \\
\text { jasa }\end{array}$ & & & & & \\
\hline 3 & $\begin{array}{l}\text { lebar } \\
\text { jalan } 8 \\
\text { meter }\end{array}$ & air PAM & 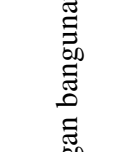 & & & $\begin{array}{c}\text { Permukiman } \\
\text { dan } \\
\text { perdagangan } \\
\text { jasa }\end{array}$ & & & & & \\
\hline 4 & $\begin{array}{l}\text { lebar } \\
\text { jalan } 12 \\
\text { meter }\end{array}$ & air PAM & 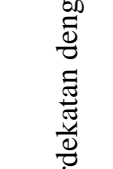 & 1 meter & $\begin{array}{l}2-3 \\
\text { lantai }\end{array}$ & $\begin{array}{l}\text { Peremukiman } \\
\text { dan } \\
\text { perdagangan } \\
\text { jasa }\end{array}$ & $\begin{array}{l}\text { Batu } \\
\text { bata }\end{array}$ & $\begin{array}{c}\text { Ada } \\
\text { namun } \\
\text { terbatas }\end{array}$ & & Tidak ada & \\
\hline 5 & $\begin{array}{l}\text { lebar } \\
\text { jalan } 8 \\
\text { meter }\end{array}$ & $\begin{array}{l}\text { air PAM } \\
\text { dan } \\
\text { aliran } \\
\text { air } \\
\text { sungai } \\
\text { kecil }\end{array}$ & 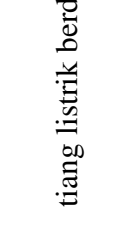 & & & $\begin{array}{l}\text { Permukiman } \\
\text { dan } \\
\text { perdagangan } \\
\text { jasa }\end{array}$ & & & & & \\
\hline 6 & $\begin{array}{l}\text { lebar } \\
\text { jalan } 12 \\
\text { meter }\end{array}$ & $\begin{array}{l}\text { air PAM } \\
\text { dan } \\
\text { aliran } \\
\text { air } \\
\text { sungai } \\
\text { kecil }\end{array}$ & & & & pergudnagan & & & & & \\
\hline
\end{tabular}

Sumber: Survei Primer, 2016

\section{KESIMPULAN}

Berdasarkan hasil analisis dan pembahasan yang telah dilakukan dalam penelitian, maka dapat disimpulkan bahwa hamper seluruh karakteristik bangunan, lingkungan dan sarana kebakaran di kelurahan Nyamplungan meningkatkan resiko kebakaran. Namun, terdapat beberapa karakteristik pembentuk
Gambar 9 Kondisi Elemen Pembentuk void Berupa Sistem Linier Terbuka

Karakteristik elemen pembentuk linkage secara visual berupa koridor kecuali pada blok 5 dan blok 6 yang berupa sisi. Elemen koridor yang menghubungkan dua tempat dengan deretan massa membentuk ruang sedangkan Elemen sisi yang menghubungkan dua tempat dengan deretan massa membentuk linier bersifat massif[10]. Elemen pembentuk linkage secara struktural berupa elemen tambahan pada semua blok. Elemen tambahan yang memberikan pola lanjutan pada suatu kawasan. Bentuk massa dan ruang bias berbeda dengan yang sudah ada tetapi pola yang terbentuk mengikuti pola kawasan yang sudah ada[11]. Semua blok juga memiliki karakteristik elemen pembentuk linkage secara kolektif yang sama berupa bentuk komposisi.

solid, void dan linkage yang dapat mengurangi resiko kebakaran yaitu elemen pembentuk linkage secara visual berupa koridor dan definisi sisi, elemen pembentuk void berupa sistem linier terbuka, dan elemen pembentuk solid berupa blok medan 


\section{DAFTAR PUSTAKA}

[1] Dinas Kebakaran Kota Surabaya.2015. Data Kebakaran Kota Surabaya. Surabaya

[2]-[6] Menteri Pekerjaan Umum, 2000. Keputusan Menteri Pekerjaan Umum Nomor 10/KPTS/2000 tentanng Ketentuan Teknis Pengamanan terhadap Bahaya Kebakaran pada Bangunan Gedung dan Lingkungan, Jakarta

[7] PLN.2010. Standar kontruksi PLN. Jakarta

[8]-[11] Zahnd, M. 1999. Perancangan Kota Secara Terpadu, Yogyakarta: Kanisius 